\title{
Hepatocyte Peroxisome Proliferator-Activated Receptor $\alpha$ Enhances Liver Regeneration after Partial Hepatectomy in Mice
}

Guomin Xie, ${ }^{* \dagger}$ Shi Yin, ${ }^{\dagger}$ Zhenzhen Zhang, ${ }^{\S}$ Dan Qi ${ }^{\dagger}$ Xia Wang, ${ }^{\dagger}$ Donghwan Kim, ${ }^{\top}$ Tomoki Yagai, ${ }^{\top}$ Chad N. Brocker, ${ }^{\top}$ Yan Wang, Frank J. Gonzalez, ${ }^{\text {"T }}$ Hua Wang, ${ }^{*} \|_{* *}$ and Aijuan Qu

From the School of Pharmacy, * and the Department of Geriatrics, ${ }^{\ddagger}$ Anhui Provincial Hospital, the Department of Oncology, " First Affiliated Hospital, and the Institute for Liver Diseases, ${ }^{* *}$ Anhui Medical University, Hefei, China; the Department of Physiology and Pathophysiology, ${ }^{\dagger}$ School of Basic Medical Sciences, Key Laboratory of Remodeling-Related Cardiovascular Diseases, Ministry of Education, Capital Medical University, Beijing, China; the Department of Infectious Diseases, ${ }^{\S}$ Peking University First Hospital, Beijing, China; and Laboratory of Metabolism, ${ }^{\nwarrow}$ National Cancer Institute, NIH, Bethesda, Maryland

Accepted for publication

October 10, 2018

Address correspondence to Aijuan Qu, M.D., Ph.D., Department of Physiology and Pathophysiology, School of Basic Medical Sciences, Capital Medical University, No. 10 Xitoutiao, Fengtai District, Beijing 100069; or Hua Wang, M.D., Ph.D., Department of Oncology, First Affiliated Hospital, Anhui Medical University, 218 Jixi Rd., Hefei, Anhui 230032, China. E-mail: aijuanqu@ccmu.edu.cn or wanghua@ahmu.edu.cn.

\begin{abstract}
Peroxisome proliferator-activated receptor $\alpha$ (PPAR $\alpha$ ) is a key nuclear receptor involved in the control of lipid homeostasis. In rodents, PPAR $\alpha$ is also a potent hepatic mitogen. Hepatocytespecific disruption of PPAR $\alpha$ inhibits agonist-induced hepatocyte proliferation; however, little is known about the exact role of PPAR $\alpha$ in partial hepatectomy $(\mathrm{PHx})$-induced liver regeneration. Herein, using hepatocyte-specific PPAR $\alpha$-deficient $\left(\right.$ Ppara $\left.^{\Delta H e p}\right)$ mice, the function of hepatocyte PPAR $\alpha$ in PHx-induced liver regeneration was investigated. PPAR $\alpha$ protein level and transcriptional activity were increased in the liver after PHx. Compared with the Ppara ${ }^{\mathrm{fl} / \mathrm{fl}}$ mice, Ppara ${ }^{\Delta \mathrm{Hep}}$ mice exhibited significantly reduced hepatocyte proliferation at 32 hours after PHx. Consistently, reduced Cond 1 and Pcna mRNA and CYCD1 and proliferating cell nuclear antigen protein were observed at 32 hours after PHx in Ppara ${ }^{\Delta \mathrm{Hep}}$ mice. Furthermore, Ppara ${ }^{\Delta \mathrm{Hep}}$ mice showed increased hepatic lipid accumulation and enhanced hepatic triglyceride contents because of impaired hepatic fatty acid $\beta$ oxidation when compared with that observed in $\mathrm{Ppara}^{\mathrm{fl} / \mathrm{fl}}$ mice. These results indicate that PPAR $\alpha$ promotes liver regeneration after $\mathrm{PHx}$, at least partially via regulating the cell cycle and lipid metabolism. (Am J Pathol 2019, 189: 272-282; https://doi.org/10.1016/j.ajpath.2018.10.009)
\end{abstract}

The liver has a remarkable ability to regenerate. A $70 \%$ partial hepatectomy (PHx) animal model is commonly used to study liver regeneration. After PHx, the hepatocyte, the main cell type of the liver, replicates through both hypertrophic and hyperplastic mechanisms. ${ }^{1}$ Liver regeneration is a compensatory hyperplasia process involving multiple growth factors, cytokines, hormones, and nuclear receptors. ${ }^{2-8}$ Almost all the cell types in liver participate in the PHx response; hepatocytes and cholangiocytes rapidly enter into the cell cycle, whereas stellate cells, Kupffer cells, and endothelial cells follow hepatocytes in the procession of regeneration, ${ }^{8}$ which takes 5 to 7 days in mice, with cell proliferation peaking at days 2 or $3 .^{2-4,8}$ In the early stage after liver regeneration, the blood concentrations of hepatocyte growth factor, epidermal growth factor, tumor necrosis factor $\alpha(\mathrm{TNF} \alpha)$, IL-6, norepinephrine, bile acids, and serotonin were rapidly increased..$^{2-7}$ It is widely accepted that PHx causes a transient increase in lipopolysaccharide levels, which stimulates Kupffer cells to produce IL-6 and TNF $\alpha$ that act on hepatocytes to induce survival and proliferation. ${ }^{9,10}$

Systemic and liver local metabolic changes are believed to trigger and participate in liver regeneration. Hypoglycemia

Supported by the National Natural Science Foundation of China grants 81100311 (S.Y.), 81470879 (S.Y.), 81770588 (H.W.), 81522009 (H.W.), 81670400 (A.Q.), and 91739120 (A.Q.); and Beijing Municipal Institutions Importation and Development of High-Caliber Talents Project CIT\&TCD20150325 (A.Q.).

G.X. and S.Y. contributed equally to this work.

Disclosures: None declared. 
Table 1 List of Real-Time Quantitative PCR Primer Sequences

\begin{tabular}{|c|c|c|c|}
\hline Genes & NCBI accession number* & Forward & Reverse \\
\hline Ppara & NM_001113418 & $5^{\prime}$-CTGCCTTCCCTGTGAACTGA-3' & 5'-ACAGAGCGCTAAGCTGTGAT-3' \\
\hline Ccna2 & NM_009828 & $5^{\prime}-$ TCGCTGCATCAGGAAGACC-3' & $5^{\prime}-\mathrm{CTTAAGAGGAGCAACCCGTCG-3^{ \prime }}$ \\
\hline Cone1 & NM_007633 & 5'-ACTTCCCGTCTTGAATTGGGG-3' & $5^{\prime}-$ AGGATGACGCTGCAGAAAGT-3' \\
\hline Pcna & NM_011045 & 5'-TCGTCTCACGTCTCCTTGGT-3' & 5'-TTTTGGACATGCTGGTGAGGT-3' \\
\hline Check1 & NM_007691 & $5^{\prime}-\mathrm{CTGGCAAAGGACTGCTTGTC-3^{ \prime }}$ & $5^{\prime}$-GTTGAACTTCTCCATAGGCACC- $3^{\prime}$ \\
\hline Prkdc & NM_011159 & $5^{\prime}-$ ACAGAGACGGTAATCACGGGT-3' & $5^{\prime}-$ CCAGCAGGAAAGCTGGGTT- $3^{\prime}$ \\
\hline Rad51 & NM_011234 & 5'-TTCACGGTTAGAGCAGTGTGG-3' & $5^{\prime}-\mathrm{TTCGGTGCATAAGCAACAGC-3^{ \prime }}$ \\
\hline G6pc & NM_008061.4 & $5^{\prime}$-GTCTTGTCAGGCATTGCTGTG- $3^{\prime}$ & $5^{\prime}$-GAATCCAAGCGCGAAACCAA-3' \\
\hline Pck1 & NM_011044.2 & $5^{\prime}-$ ATGAAAGGCCGCACCATGTA-3' & 5'-GGGCGAGTCTGTCAGTTCAA-3' \\
\hline$P k m$ & NM_001253883.1 & $5^{\prime}-$ ATGCAGCACCTGATAGCTCG-3' & $5^{\prime}$-AGGTCTGTGGAGTGACTGGA-3' \\
\hline Cyp4a10 & NM_010011.3 & 5'-AGGAGCCAGGAACTGCATTG-3' & 5'-GACCCTGGTAGGATCTGGCA-3' \\
\hline Cyp4a14 & NM_007822.2 & $5^{\prime}-\mathrm{TTGCTCACGAGCACACAGAT-3^{ \prime }}$ & $5^{\prime}-\mathrm{TCCTCCATTCTGGCAAACAAGA-3'}$ \\
\hline Cpt2 & NM_009949.2 & $5^{\prime}$-ATCTCAGGCCCCTGGTTTGA-3' & $5^{\prime}$-АTCTCAGGCCCCTGGTTTGA-3' \\
\hline Ehhadh & NM_023737.3 & 5'-CGGTCAATGCCATCAGTCCA-3' & $5^{\prime}$-AGCACCTGCACAGAAGTTGT-3' \\
\hline Hmgcs2 & NM_008256.4 & $5^{\prime}-$ AGAAATCCCTGGCTCGGTTG- $3^{\prime}$ & $5^{\prime}-$ AGCTTTAGACCCCTGAAGGC- $3^{\prime}$ \\
\hline Txnip & NM_001009935.2 & 5'-GAAGGCTTTTCTCGATCGCC-3' & $5^{\prime}$-GGCAGACACTGGTGCCATTA-3' \\
\hline Vnn1 & NM_011704.3 & $5^{\prime}$-GCATGCTGTGATCCTGCCTAA-3' & $5^{\prime}-\mathrm{TAATGTGCGCACCCTGCT-3^{ \prime }}$ \\
\hline Cpt1a & NM_013495.2 & $5^{\prime}-\mathrm{TCGGTGAGCCTGGCCT}-3^{\prime}$ & 5'-TTGAGTGGTGACCGAGTCTG-3' \\
\hline
\end{tabular}

*Available from https://www.ncbi.nlm.nih.gov/nuccore.

NCBI, National Center for Biotechnology Information.

and increased circulating insulin levels also occur soon after PHx. ${ }^{11-13}$ The liver presents transient steatosis on day 2 or 3 after PHx, which could influence liver regeneration. ${ }^{11,14}$ An early study shows that mice rapidly develop hypoglycemia after the operation, which causes adipose tissue lipolysis and leads to periphery lipid redistribution in the regenerating liver. ${ }^{15}$ This study suggests that hepatic steatosis after PHx could promote liver regeneration. ${ }^{15}$ However, liver regeneration was impaired after $\mathrm{PHx}$ in hepatic steatosis mice, ${ }^{16}$ mice with genetic obesity, ${ }^{17}$ or mice fed with a high-fat diet. $^{18}$ Disruption of hepatic lipid accumulation also decreases liver regeneration after PHx in mice. ${ }^{19}$ Until now, the underlying mechanisms of these results remain unclear.

Many regulators of lipid droplet formation and peripheral lipid mobilization were reported to participate in liver regeneration, such as farnesoid X receptor, ${ }^{20,21}$ caveolin- $1,{ }^{22,23}$ and peroxisome proliferator-activated receptors (PPARs). ${ }^{24-26}$ $\operatorname{PPAR} \alpha$ is a ligand-activated nuclear receptor, which plays an important role in regulating liver and skeletal muscle fatty acid metabolism and glucose homeostasis. ${ }^{27}$ Short exposure of mice and rats to peroxisome proliferator chemicals and fibrate drugs leads to hepatocyte proliferation and hepatomegaly through activation of PPAR $\alpha .{ }^{28-30}$ Chronic exposure to hypolipidemia drugs, such as WY-14643 and fenofibrate, results in prolonged PPAR $\alpha$ activation, leading to hepatocellular carcinoma in mice and rats. ${ }^{31}$ A previous study revealed that increased PPAR $\alpha$ signaling influenced the cell cycle regulation of late-phase liver regeneration. ${ }^{32}$ However, using PPAR $\alpha$ whole-body knockout mice (Ppara-null mice), one report found a delayed hepatocyte proliferation after $\mathrm{PHx}$, accompanied by decreased expression of Ccndl and Myc involved in cell cycle regulation and impaired RAS membrane association, which indicate that PPAR $\alpha$ could promote cell proliferation after PHx. ${ }^{26,31}$ In summary, the findings from these studies suggest that PPAR $\alpha$ plays a key role in the liver regeneration program, but the definitive role of $\operatorname{PPAR} \alpha$ in liver cell proliferation after $\mathrm{PHx}$ remains unresolved. A recent study revealed that WY-14643-activated PPAR $\alpha$ induces cell proliferation, which is mainly dependent on hepatocyte PPAR $\alpha{ }^{33}$ rather than PPAR $\alpha$ expressed in nonparenchymal cells, indicating the function of PPAR $\alpha$ in hepatocyte proliferation is cell type specific. However, the precise effect of hepatocyte PPAR $\alpha$ on liver regeneration after PHx remains unknown. In this study, using mice with conditional ablation of PPAR $\alpha$ in hepatocyte (Ppara ${ }^{\Delta \mathrm{Hep}}$ mice), hepatocyte $\mathrm{PPAR} \alpha$ was found to promote liver regeneration after PHx via regulating cell cycle and lipid metabolism.

\section{Materials and Methods}

\section{Animals}

Male 8- to 10-week-old mice were used in the present study. Hepatocyte-specific PPAR $\alpha$-deficient mice $\left(\right.$ Ppara $^{\Delta \mathrm{Hep}}$ 


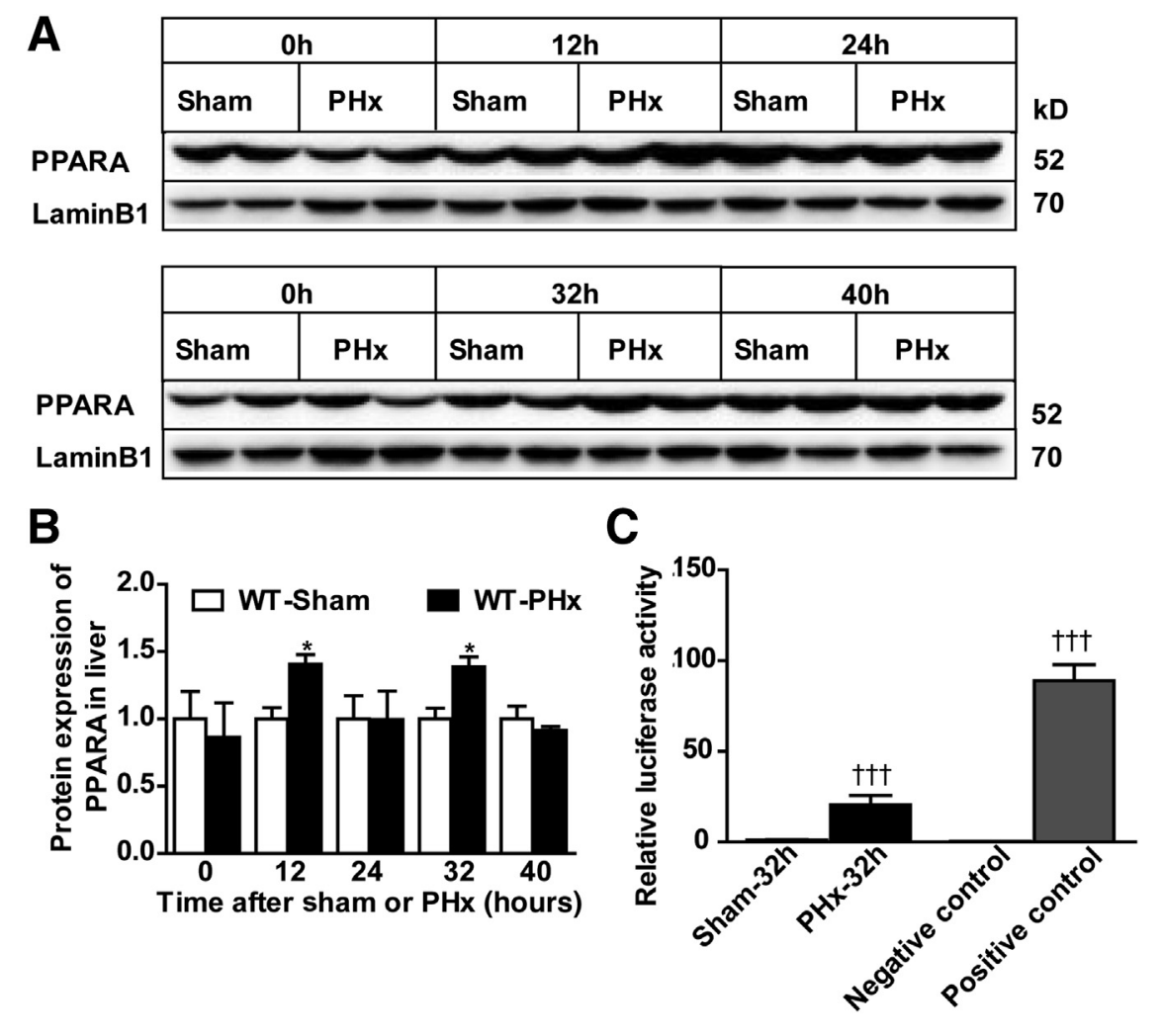
Figure 1 Increased PPAR $\alpha$ activity in wild- type (WT) mouse liver after PHx. A and B: West- ern blot analysis of PPAR $\alpha$ protein expression in WT livers after PHx or sham operation. C: Lucif- erase activity of PPARA response element repeat mice after sham or $\mathrm{PHx}$, negative control, and positive control. Data are expressed as means \pm SD (B and $\mathbf{C}) . n=3$ (A and $\mathbf{B}) ; n=5$ (C). ${ }^{*} P<0.05$ versus WT-sham; ${ }^{\dagger \dagger} P<0.001$ versus sham or negative control.

mice) were generated, as described, ${ }^{33}$ and Ppara $^{\mathrm{f} / \mathrm{fl}}$ mice were used as littermate controls. These mice were kept on a standard 12-hour light/dark cycle with free access to chow diet and water. The animal studies were performed in accordance with protocols approved by the Capital Medical University Animal Care and Use Committee.

To investigate the transcriptional activity of PPAR $\alpha$ after $\mathrm{PHx}$, transgenic mice containing a transgene expressing luciferase under control of a PPARA response element repeat were used. These mice were generated, as previously described, ${ }^{34}$ and obtained from Charles River Company (Boston, MA). The animal studies were performed in the Laboratory of Metabolism, National Cancer Institute, NIH (Bethesda, MD), in accordance with protocol approved by the National Cancer Institute Animal Care and Use Committee.

\section{Partial Hepatectomy Model and Tissue Harvesting}

The two-third partial hepatectomy (PHx) surgery was performed as previously described. ${ }^{35-37}$ Mice were injected with 5 -bromo-2-deoxyuridine $(50 \mathrm{mg} / \mathrm{kg}$ body weight) 2 hours before sacrificing at the indicated time points. Liver tissues were formalin fixed or frozen in OCT for cryosection, whereas the remaining liver tissue was snap frozen for further analysis.

\section{Hematoxylin-Eosin Staining and} Immunohistochemistry Staining

Paraffin-embedded liver tissues were cut into sections (4 $\mu \mathrm{m}$ thick) for hematoxylin-eosin and immunohistochemistry staining. Hematoxylin-eosin staining was performed following standard methods. Immunohistochemistry analysis was performed using antibodies against 5-bromo-2deoxyuridine (BD Bioscience, San Jose, CA), as previously described.

\section{0il Red 0 Staining}

For oil red O staining, OCT-embedded blocks were cut into sections $(10 \mu \mathrm{m}$ thick) and stained with oil red $\mathrm{O}$ solution, as previously described. ${ }^{38}$

\section{Quantitative Real-Time RT-PCR}

Total RNA was extracted from $P p a r a^{\mathrm{f} / \mathrm{fl}}$ and $P p a r a^{\Delta \mathrm{Hep}}$ livers using Trizol reagent (Life Technologies, Carlsbad, CA), then reverse transcripted into cDNA with GoScript Reverse Transcriptase (Promega, Madison, WI) and used for quantitative real-time RT-PCR analysis with SYBR Green premix (TaKaRa, Nojihigashi, Kusatsu, Shiga, Japan). Quantitative real-time RT-PCR assays were performed on CFX Connect Real-Time System (Bio-Rad, Hercules, CA). Expression of 

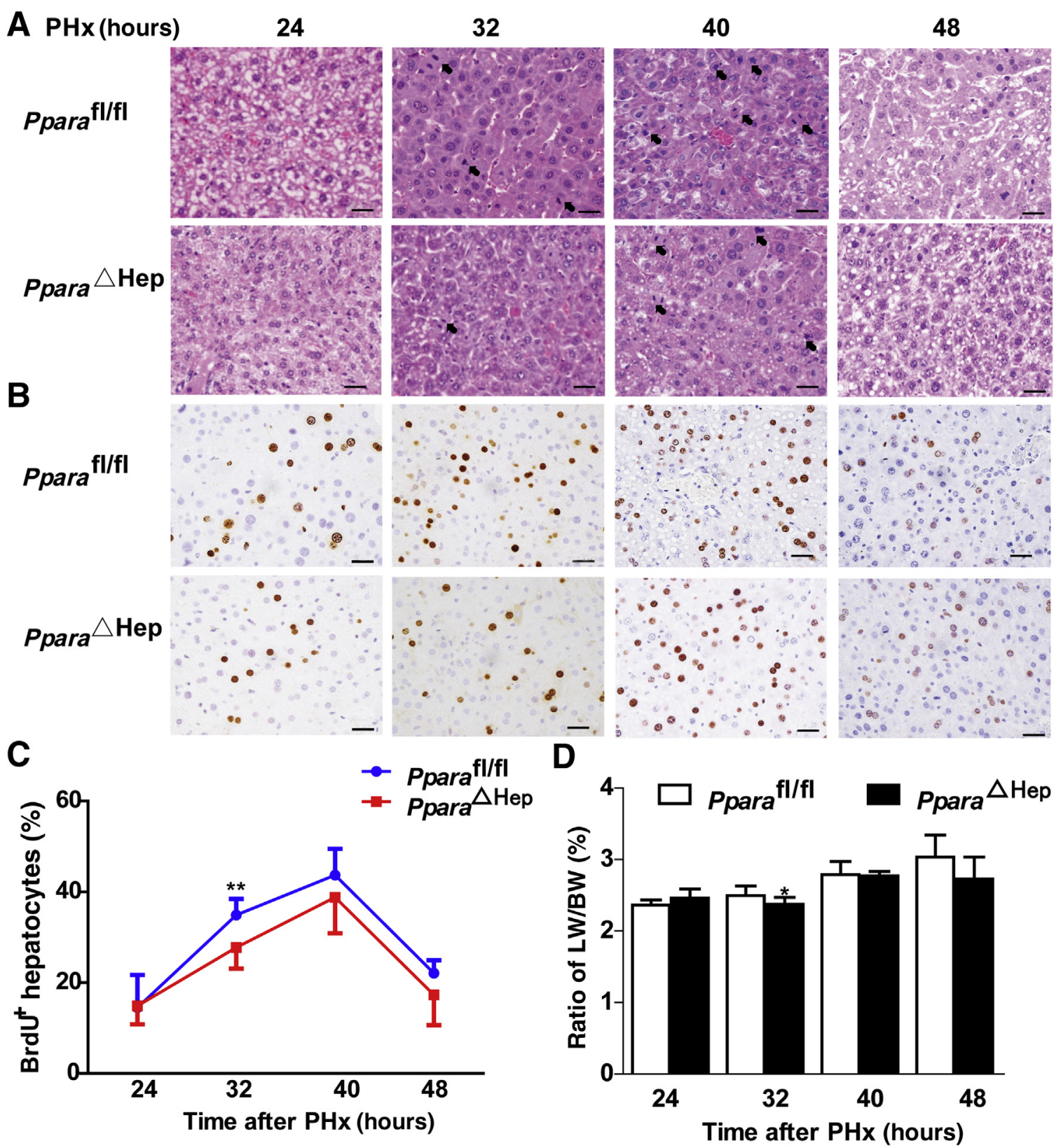

Figure 2 Disruption of PPAR $\alpha$ in hepatocyte inhibits liver regeneration after PHx. A: Representative images of hematoxylin and eosin staining of liver tissues from Ppara ${ }^{\mathrm{\Delta Hep}}$ mice and Ppara ${ }^{\mathrm{fl} / \mathrm{fl}}$ mice at 24, 32, 40, and 48 hours. The arrows refer to mitotic hepatocytes. B: Representative images of 5-bromo-2deoxyuridine (BrdU) staining of residual liver in two groups of mice at 24, 32, 40, and 48 hours after PHx. C: BrdU-positive hepatocyte/total hepatocyte ratios per field of two groups at indicated time points. D: The ratio of liver weight/body weight (LW/BW) of the two groups at different time points. Data are expressed as means \pm SD (D). $n=5$ Ppara ${ }^{\mathrm{fl} / \mathrm{fl}}$ mice; $n=11$ Ppara $^{\Delta \mathrm{Hep}}$ mice at $24,32,40$ and 48 hours after PHx. ${ }^{*} P<0.05,{ }^{* *} P<0.01$ versus $P$ para ${ }^{\mathrm{fl} / \mathrm{fl}}$ mice. Scale bars $=20 \mu \mathrm{m}(\mathbf{A}$ and $\mathbf{B})$. Original magnification, $\times 400(\mathbf{A}$ and $\mathbf{B})$.

target genes was normalized to that of the housekeeping gene $\beta$-actin mRNA. The primers are listed in Table 1.

\section{Protein Extraction and Western Blot Analysis}

Whole-cell lysate was extracted using radioimmunoprecipitation assay buffer (Applygen, Beijing, China), and nuclear extraction was done with a nuclear and cytoplasmic protein extraction kit (KeyGENBioTECH,
Nanjing, China). The protein concentration was measured using the bicinchoninic acid protein assay kit (Thermo Scientific, Waltham, MA). Specific primary antibodies used were as follows: antibody against PPAR $\alpha$ and LaminB1 from Abcam (Cambridge, UK), cyclin D1 and $\beta$-actin antibodies from Cell Signaling Technology (Boston, MA), and proliferating cell nuclear antigen (PCNA) antibody from Santa Cruz Biotechnology (Dallas, TX). The dilutions were 1:1000 in 5\% bovine serum albumin. After incubating 


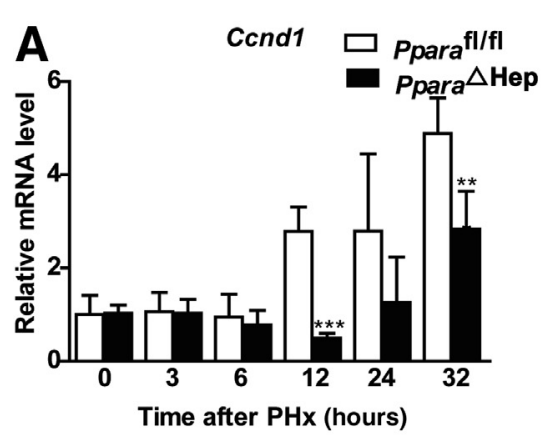

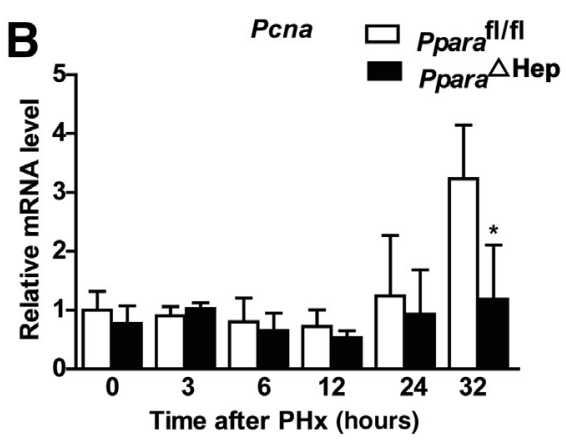

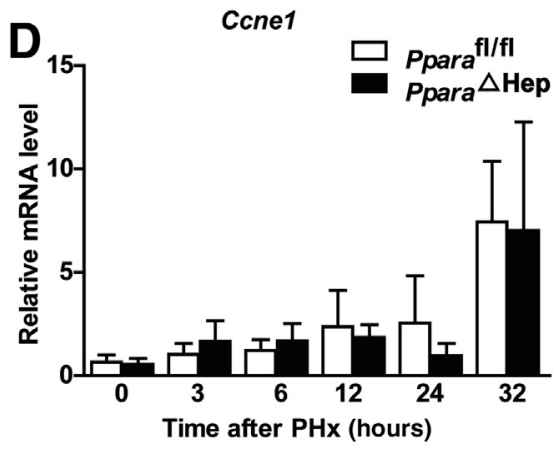

Figure 3 Disruption of PPAR $\alpha$ in hepatocytes results in decreased cell cycle gene expression after PHx. A-D: Real-time PCR analysis of cell cycle-related genes Cona2, Cond1, Cone1, and Pcna mRNA levels in Ppara ${ }^{\Delta \mathrm{Hep}}$ and Ppara ${ }^{\mathrm{fl} / \mathrm{fl}}$ mice at different time points after PHx. E and F: Western blot analysis of CYCD1 and proliferating cell nuclear antigen (PCNA) protein expression in Ppara $^{\text {Hep }}$ mice and Ppara ${ }^{\mathrm{fl} / \mathrm{fl}}$ mice at 0, 3, 6, 12, 24, and 32 hours after PHx. Data are expressed as means \pm SD (A-D). $n=5$ (A-D). ${ }^{*} P<0.05$ ${ }^{* *} P<0.01$, and ${ }^{* * * P}<0.001$ versus $P$ para ${ }^{\mathrm{fl} / \mathrm{fl}}$. ACTB, $\beta$-actin.

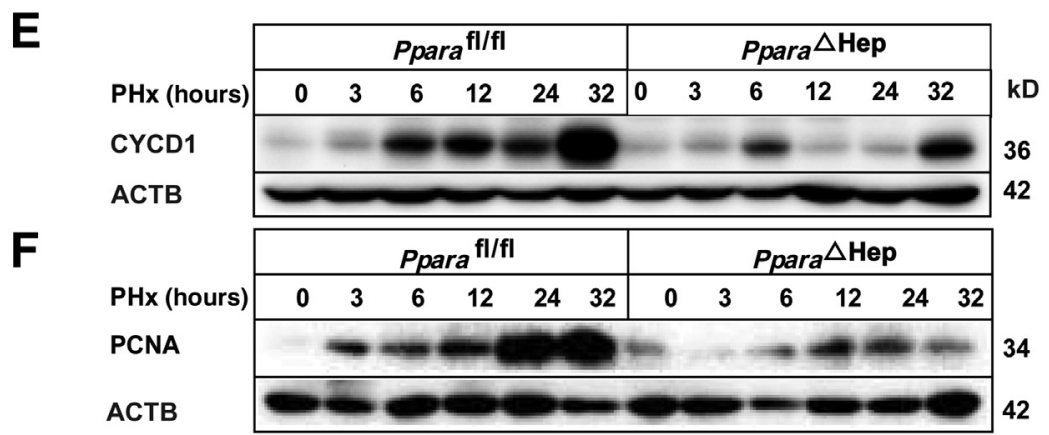

with horseradish peroxidase-conjugated secondary antibody, the immunocomplexes were visualized with FluorChem-R (ProteinSimple, San Jose, CA). Total protein levels were normalized to $\beta$-actin (ACTB), and nuclear protein levels were normalized to LaminB1.

\section{Microarray Analysis}

Microarray analysis was performed by CNKINGBIO Company (China). Total RNA was extracted and purified, and the quality was examined. Purified RNA was labeled and hybridized to an AffymetrixHuman Gene 1.1 ST array plate (Affymetrix, Santa Clara, CA). Hybridization, washing, and scanning were performed on an Affymetrix GeneTitan platform following the instruction. Kyoto Encyclopedia of Genes and Genomes is a knowledge base for systematic analysis of gene functions, linking genomic information with higher-order functional information, and now is used widely for pathway-related analysis. The hypergeometric distribution was used to calculate the pathway enrichment, and false discover rate was used to adjust the $P$ values for multiple comparisons.

\section{Hepatic Triglyceride Measurement}

Hepatic triglycerides were extracted in $50 \mathrm{mmol} / \mathrm{L}$ Tris buffer, homogenized, and incubated at $37^{\circ} \mathrm{C}$ with shaking overnight. A triglyceride measurement kit (Applygen) was used following the manufacturer's instruction to measure triglyceride contents.

\section{Serum $\beta$-Hydroxybutyrate Assay}

Serum concentrations of $\beta$-hydroxybutyrate were detected by enzyme-linked immunosorbent assay (NanJingJianCheng Bioengineering Institute, Nanjing, China), strictly according to the manufacturer's instruction.

\section{Luciferase Assay}

PPARA response element repeat mice, aged 8 to 10 weeks, were subjected to PHx or sham surgery, as outlined in the original protocol. Thirty-two hours after surgery, livers were harvested and luciferase activity was measured by the Dual-Luciferase Assay System and normalized by protein 

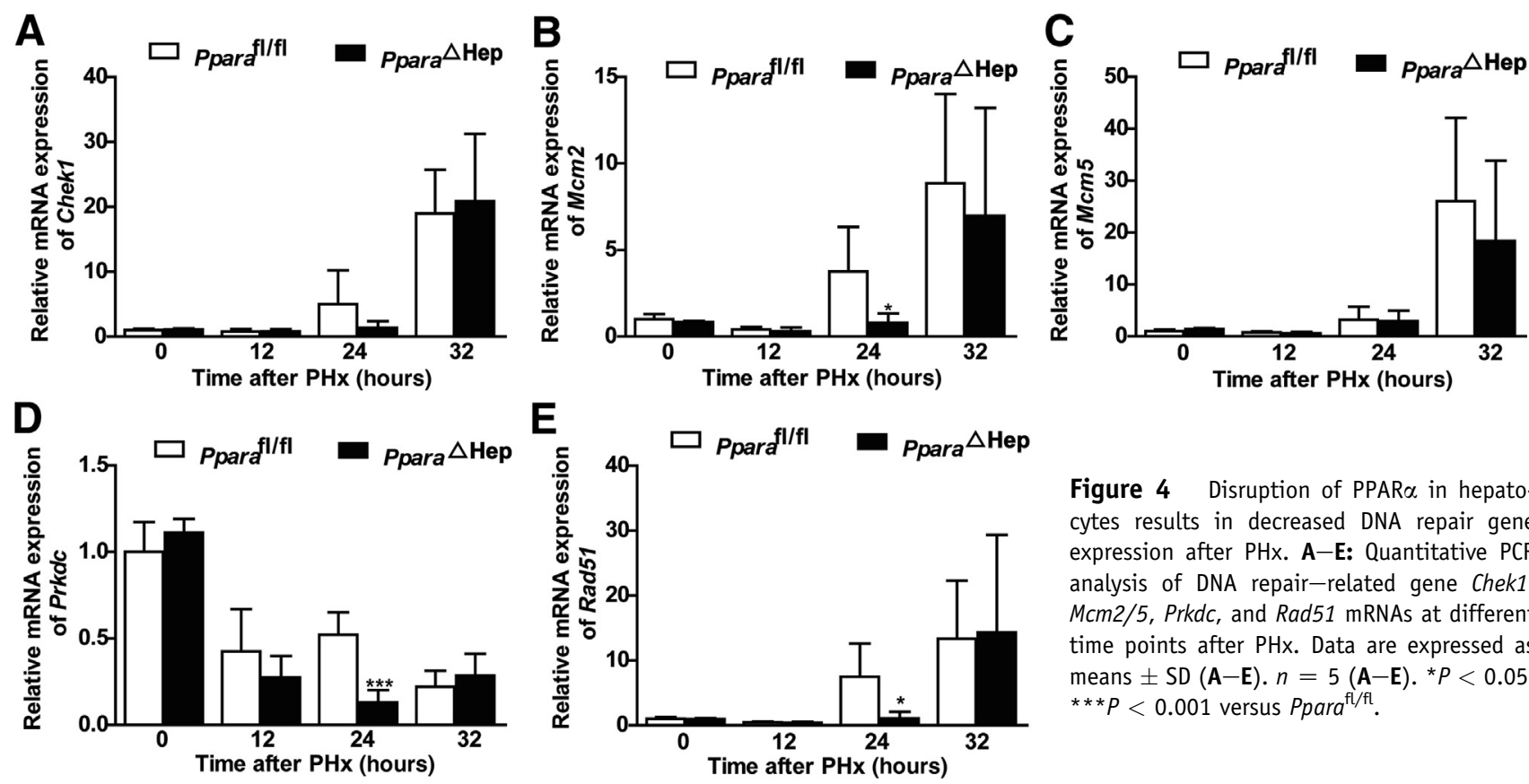

Figure 4 Disruption of PPAR $\alpha$ in hepatocytes results in decreased DNA repair gene expression after PHx. A-E: Quantitative PCR analysis of DNA repair-related gene Chek1, Mcm2/5, Prkdc, and Rad51 mRNAs at different time points after PHx. Data are expressed as means $\pm \mathrm{SD}(\mathbf{A}-\mathbf{E}) . n=5$ (A-E). ${ }^{*} P<0.05$, $* * * P<0.001$ versus Ppara ${ }^{\mathrm{fl} / \mathrm{fl}}$.

concentration. PPARA response element repeat mice treated with PPAR $\alpha$ agonist $\mathrm{Wy}-14643$ were served as positive control, and nontreatment served as negative control.

\section{Statistical Analysis}

All data are presented as means \pm SD. Significant difference between groups was determined using unpaired $t$-test. Values obtained from three or more groups were determined by one-factor analysis of variance (ANOVA) followed by Tukey's post hoc test using GraphPad Prism5.0 software (GraphPad Software, San Diego, CA). $P<0.05$ was considered statistically significant.

\section{Results}

\section{Increased PPAR $\alpha$ Expression in the Liver after PHx}

PPAR $\alpha$ controls $\beta$-oxidation in liver and serves as a potent hepatic mitogen in rodents. ${ }^{39}$ To investigate the influence of PPAR $\alpha$ on liver regeneration after PHx, PPAR $\alpha$ and retinoid $\mathrm{X}$ receptor $\alpha$ protein expression was determined by Western blot analysis. PPAR $\alpha$ protein level was increased at 12 and 32 hours after PHx (Figure 1, A and B). However, retinoid $\mathrm{X}$ receptor $\alpha$ protein levels were comparable between sham and PHx surgery (Supplemental Figure S1). To further assess the change of PPAR $\alpha$ after $\mathrm{PHx}$, in vivo luciferase assays were performed after PHx or sham at 32 hours. Luciferase activity was significantly increased after PHx surgery compared with sham-operated mice (Figure 1C). These results indicate that PPAR $\alpha$ may be involved in PHx-induced liver regeneration.

Disruption of PPAR $\alpha$ in Hepatocyte Inhibits Liver Regeneration after $\mathrm{PHx}$

To further study the definite role of hepatocyte PPAR $\alpha$ in PHx-induced liver regeneration, hepatocyte-specific PPAR $\alpha$-deficient $\left(\right.$ Ppara $\left.^{\Delta \mathrm{Hep}}\right)$ mice were used. $^{33}$ The knockout efficiency was confirmed by real-time quantitative PCR and Western blot analysis (Supplemental Figure S2). When subjected to PHx, Ppara $^{\Delta \text { Hep }}$ mice exhibited significantly decreased mitosis in hepatocytes at 32 hours compared with Ppara $^{\mathrm{f} / \mathrm{fl}}$ mice (Figure 2A). BrdU incorporation showed that peak hepatocyte proliferation appears at 40 hours after PHx in both Ppara ${ }^{\mathrm{fl} / \mathrm{fl}}$ and Ppara ${ }^{\Delta \mathrm{Hep}}$ mice (Figure 2, B and C). However, Ppara ${ }^{\Delta \text { Hep }}$ mice showed significantly reduced hepatocyte proliferation at 32 hours after PHx compared with Ppara ${ }^{\mathrm{f} / \mathrm{fl}}$ mice (Figure 2C). Consistently, the liver weight/body weight ratio after $\mathrm{PHx}$ also decreased in Ppara ${ }^{\Delta \mathrm{Hep}}$ mice (Figure 2D). Taken together, these results suggest that liver regeneration was impaired in Ppara $^{\Delta \mathrm{Hep}}$ mice after PHx compared with Ppara $^{\mathrm{fl} / \mathrm{fl}}$ mice.

Disruption of PPAR $\alpha$ in Hepatocytes Results in Decreased Cell Cyclin and DNA Repair Gene Expression after PHx

To further confirm whether hepatocyte PPAR $\alpha$ deficiency inhibits the cell cycle after PHx, the kinetics of key cell cycle proteins, including CYCD1, CYCA2, CYCE1, and 
A

Up-regulated gene pathway enrichment

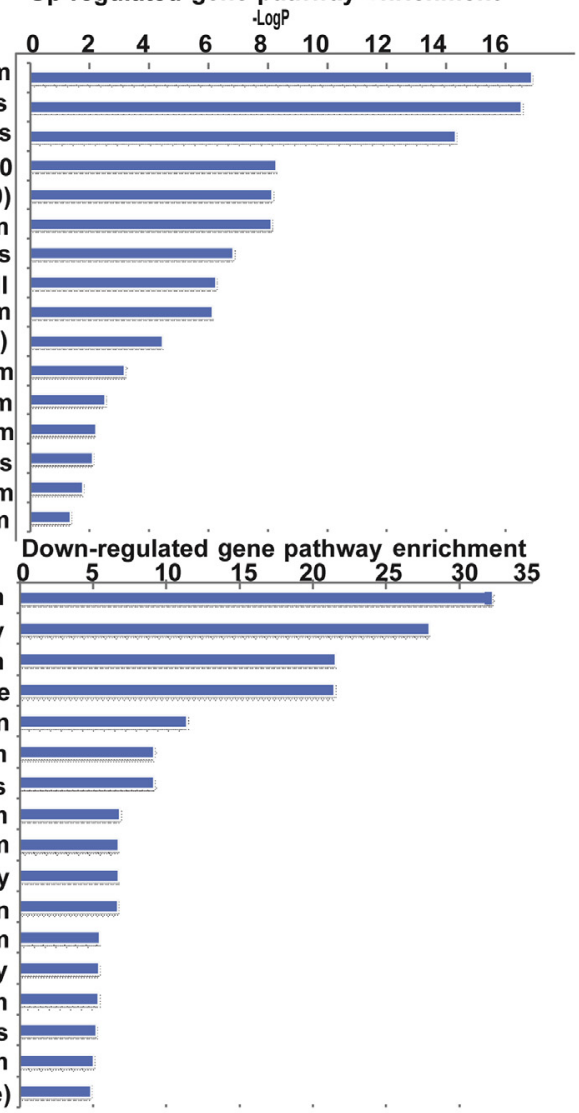

Figure 5 Microarray analyses for hepatic gene profiles from hepatocyte PPAR $\alpha$-deficient mice at 12 hours after PHx. A: Up-regulated gene pathways in Ppara $^{\Delta \mathrm{Hep}}$ mice compared with control mice at 12 hours after PHx. B: Down-regulated gene pathways in Ppara ${ }^{\Delta \mathrm{Hep}}$ mice compared with Ppara ${ }^{\mathrm{fl} /}$ $\mathrm{fl}$ mice at 12 hours after $\mathrm{PHx}$, as determined by microarray analysis. C: Quantification of Cyp4a10, Cyp4a14, Cpt2, Ehhadh, G6pc, Hmgcs2, Txnip, and $V n n 1$ mRNAs in Ppara ${ }^{\Delta \mathrm{Hep}}$ and Ppara ${ }^{\mathrm{fl} / \mathrm{fl}}$ mice. Data are expressed as means \pm SD (C). $n=4(\mathbf{A}-\mathbf{C})$. ${ }^{*} P<0.05,{ }^{* *} P<0.01$ versus $P$ para ${ }^{\mathrm{fl} / \mathrm{fl}}$. AMPK, adenosine $5^{\prime}$-monophosphate-activated protein kinase; TCA, tricarboxylic acid cycle.

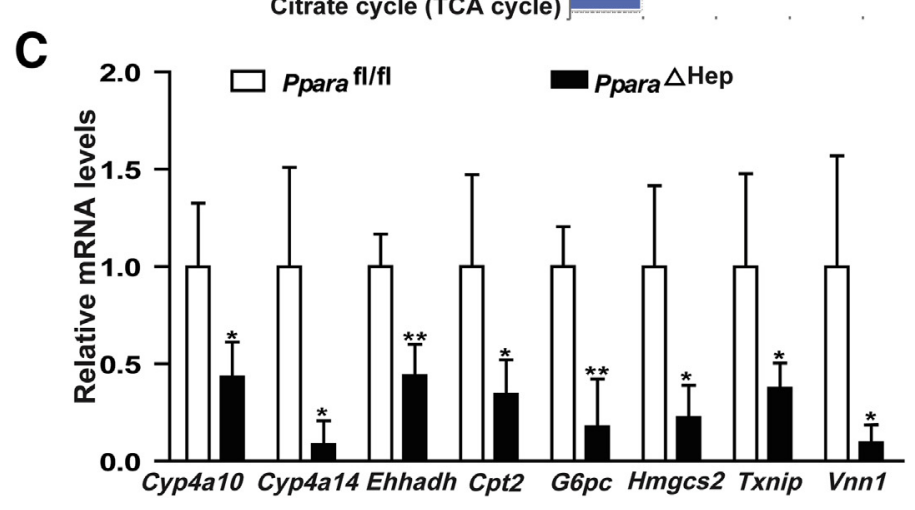

PCNA expression, were measured. Ccna2 and Ccne1 mRNA levels were comparable between Ppara $^{\mathrm{fl} / \mathrm{fl}}$ and Ppara $^{\Delta \mathrm{Hep}}$ mice; however, Ccndl mRNA, expressed during $\mathrm{G}_{1}-\mathrm{S}$ phase progression, was significantly decreased in Ppara $^{\Delta \mathrm{Hep}}$ mice (Figure 3, A-C) after PHx compared with Ppara $^{\mathrm{f} / \mathrm{fl}}$ mice, and Pcna mRNA levels also decreased at 32 hours after PHx compared with Ppara $^{\mathrm{fl} / \mathrm{fl}}$ mice (Figure 3D), consistent with BrdU incorporation assay (Figure 2). Finally, the CYCD1 and PCNA protein levels were determined in Ppara $^{\mathrm{fl} / \mathrm{fl}}$ and Ppara $^{\Delta \mathrm{Hep}}$ mice after PHx at 0, 3, 6, 12, 24, and 32 hours. Ppara ${ }^{\Delta \mathrm{Hep}}$ mice showed a decrease of CYCD1 protein expression at different time points after PHx compared with that in Ppara $^{\mathrm{fl} / \mathrm{fl}}$ mice (Figure 3E). PCNA protein also decreased at 12, 24, and 32 hours after $\mathrm{PHx}$ in contrast with Ppara $^{\mathrm{fl} / \mathrm{fl}}$ mice (Figure $3 \mathrm{~F}$ ). These results suggest that hepatocyte PPAR $\alpha$ may regulate cell proliferation by inducing cell cycle-related gene expression, which is in agreement with previous findings. ${ }^{40}$

It is well established that STAT3 and NF- $\kappa \mathrm{B}$ signaling pathways are activated in the early stage of liver regeneration. ${ }^{4}$ Activation of STAT3 and NF- $\kappa$ B was found at the early time points of 3 and 6 hours after PHx, as revealed by Western blot analyses (Supplemental Figure S3). ${ }^{27}$ Surprisingly, the phosphorylated STAT3 level was slightly higher at 6 and 12 hours after PHx in Ppara $^{\Delta \mathrm{Hep}}$ mice, and phosphorylated NF- $\mathrm{B}$ was also higher at 0 and 3 hours after PHx in Ppara ${ }^{\Delta \mathrm{Hep}}$ mice when compared with that in Ppara $^{\mathrm{fl} / \mathrm{fl}}$ mice (Supplemental Figure S3). Activation of STAT3 and NF- $\kappa$ B was found to contribute to early liver regeneration after PHx. ${ }^{4,9}$ Despite the slight increase in 
A

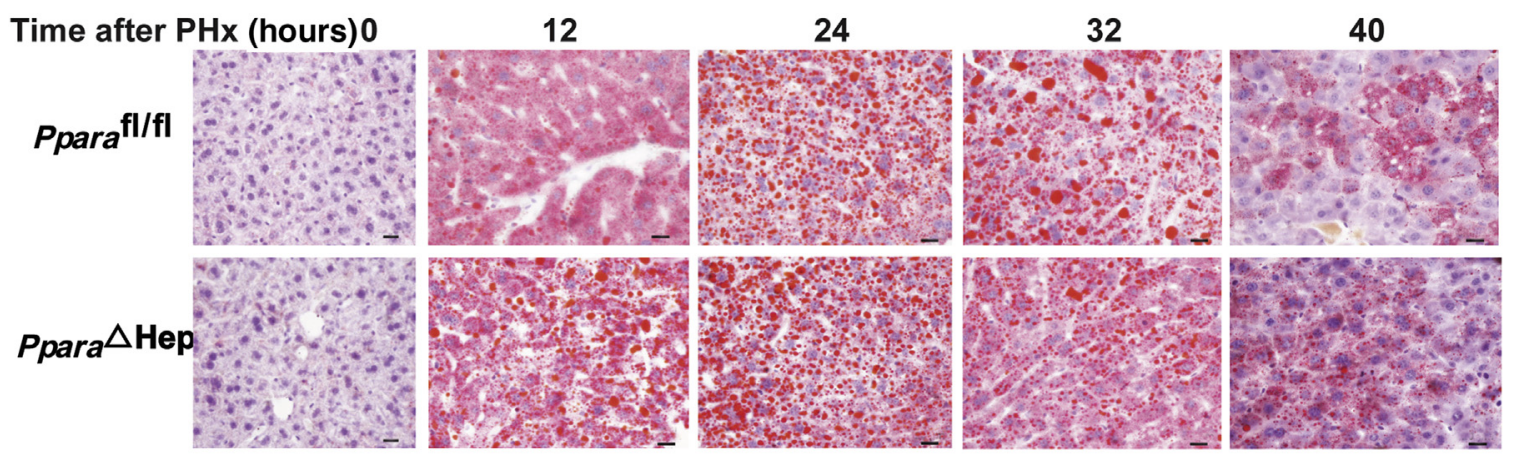

B
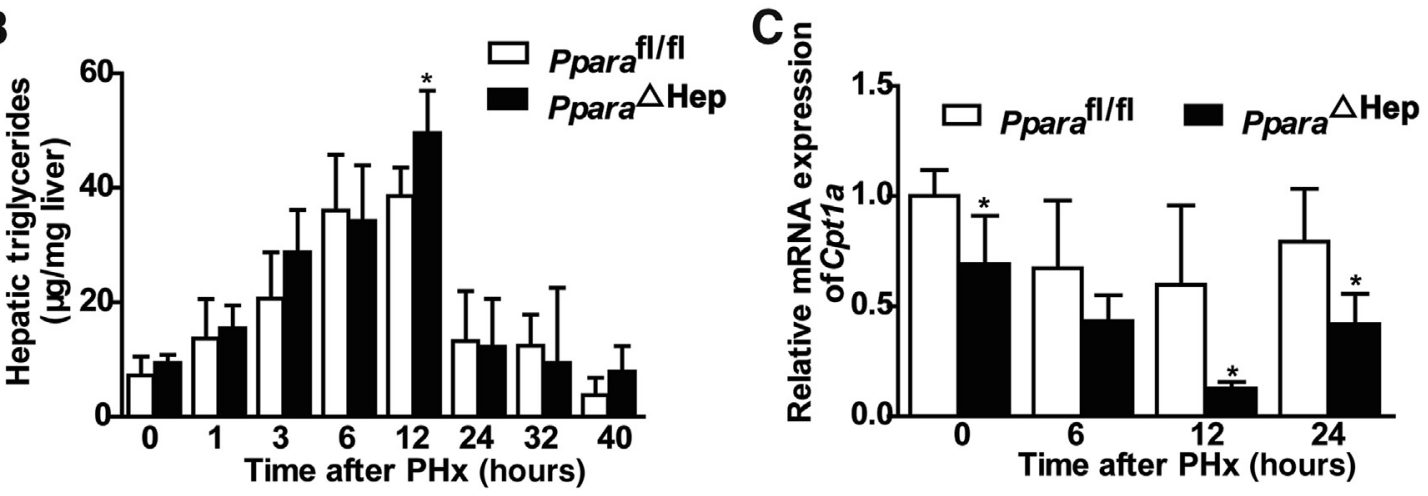

D

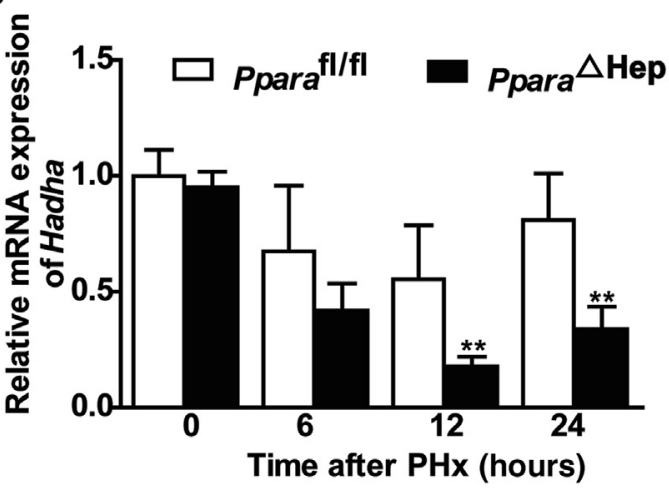

$\mathbf{E}$

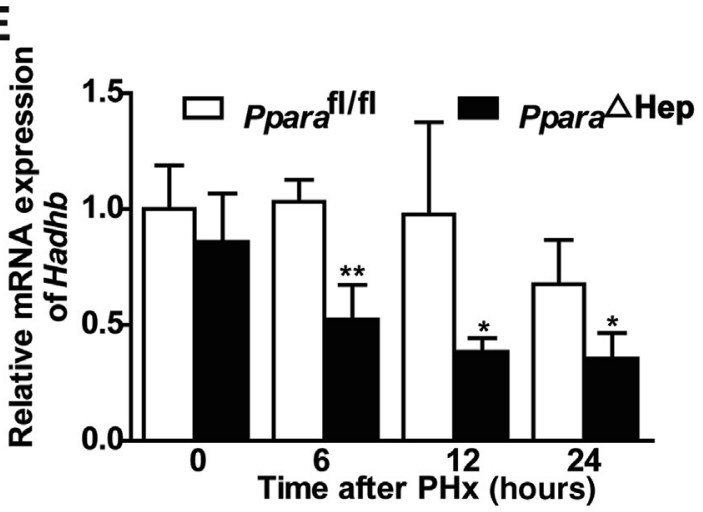

Figure 6 Hepatic PPAR $\alpha$ deficiency promotes hepatic lipid accumulation during liver regeneration. A: Representative images for oil red 0 staining of liver tissues from Ppara ${ }^{\Delta \mathrm{Hep}}$ mice and Ppara ${ }^{\mathrm{fl} / \mathrm{fl}}$ mice at 0, 12, 24, 32, and 40 hours. B: Hepatic triglyceride content in liver tissues. C-E: Fatty acid $\beta$-oxidation related Cpt1a and Hadha/b mRNAs. Data are expressed as means \pm SD $(\mathbf{B}-\mathbf{E}) . n=5(\mathbf{B}-\mathbf{E}) .{ }^{*} P<0.05,{ }^{* *} P<0.01$ versus Ppara ${ }^{\mathrm{fl} / \mathrm{fl}}$. Scale bars $=20 \mu \mathrm{m}(\mathbf{A})$. Original magnification, $\times 400(A)$.

activation of STAT3 and NF- $\kappa$ B in the early stages of PHx, the decreased cell cycle-related protein expression in Ppara $^{\Delta \mathrm{Hep}}$ mice suggested that the hepatocyte-specific PPAR $\alpha$-stimulated cell proliferation is STAT3/NF- $\kappa$ B independent.

Increased reactive oxygen species are found in liver after PHx, which could damage cellular DNA. ${ }^{41}$ A previous study demonstrated that hepatic nonparenchymal cell DNA repair gene activation was dependent on PPAR $\alpha .^{42}$ Accordingly, hepatocyte PPAR $\alpha$ may play a role in regulating DNA repair. DNA repair gene mRNA Rad51, Prkdc, and $M c m 2$ were decreased at 24 hours in ppara $^{\Delta \text { Hep }}$ mice when compared with that in Ppara ${ }^{\mathrm{f} / \mathrm{fl}}$ mice (Figure 4).
Microarray Analysis for Hepatic Gene Profile Changes from Hepatocyte PPAR $\alpha$-Deficient Mice at 12 Hours after $\mathrm{PHx}$

$\operatorname{PPAR} \alpha$ acts as the master of fatty acid oxidation in liver; however, the changes of its target genes after PHx and the consequent effects on regenerative genes were unknown. At 12 to 24 hours after PHx, the mice develop marked steatosis. ${ }^{11}$ Therefore, the time point of 12 hours after PHx was chosen to perform microarray analysis. Hepatic mRNA profiles were examined in Ppara $^{\Delta \mathrm{Hep}}$ and Ppara $^{\mathrm{f} / \mathrm{fl}}$ mice liver at 12 hours after PHx (Gene Expression Omnibus database, https://www. 
A
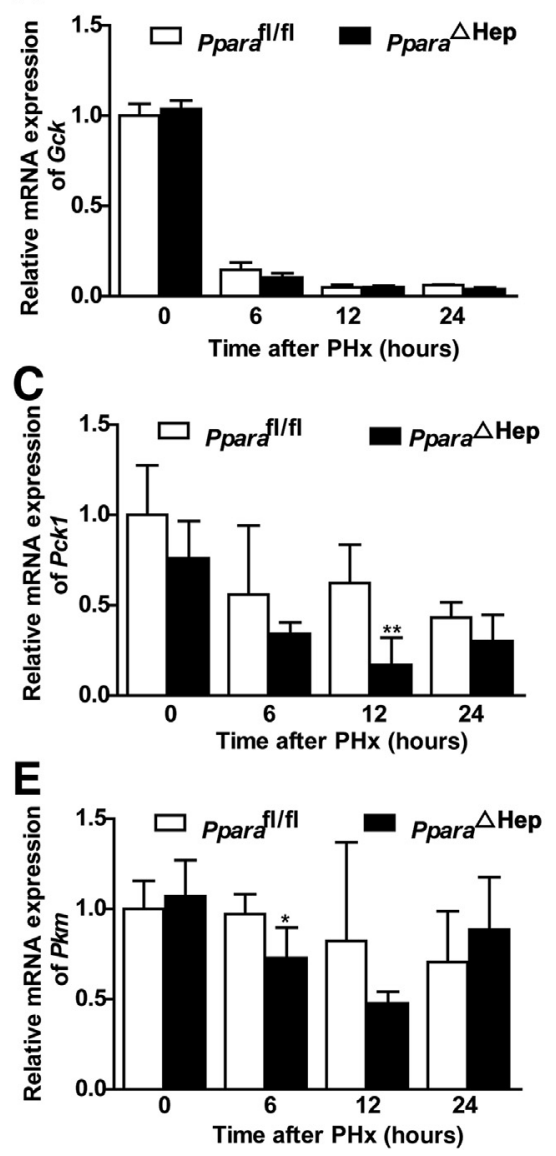

B

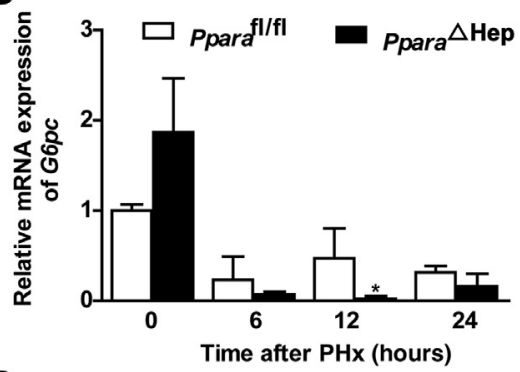

D

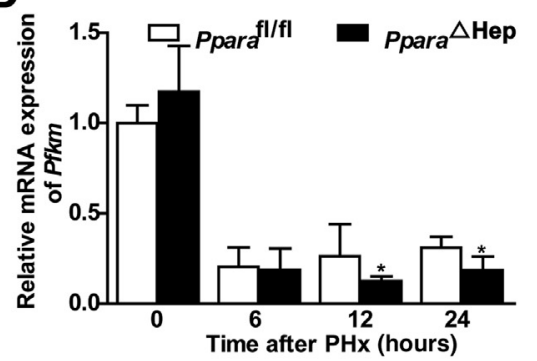

$\mathbf{F}$

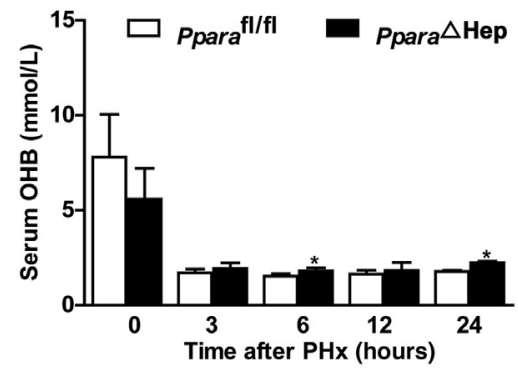

Figure 7 Hepatic PPAR $\alpha$ deficiency reduces hepatic glucose metabolism gene expression during liver regeneration. $\mathbf{A}-\mathbf{E}$ : $m R N A$ expression of gluconeogenesis genes G6pc and Pck1 (A and B) and glycolysis genes $G c k, P k m$, and $P f k m(\mathbf{C}-\mathbf{E})$. F: Serum hydroxybutyrate levels after $\mathrm{PHx}$ at 0, 3, 6, 12 , and 24 hours in Ppara ${ }^{\Delta \mathrm{Hep}}$ and Ppara ${ }^{\mathrm{fl} / \mathrm{fl}}$ mice. Data are expressed as means \pm SD (A-F). $n=5$ $(\mathbf{A}-\mathbf{F}) .{ }^{*} P<0.05,{ }^{*} P<<0.01$ versus $P$ para ${ }^{\mathrm{fl} / \mathrm{fl}}$. ncbi.nlm.nih.gov/geo; accession number GSE114223). Pathway enrichment analysis showed that compared with control mice, the up-regulated genes in Ppara $^{\Delta \mathrm{Hep}}$ mice are mainly involved in drug metabolism and detoxification and the cytochrome $\mathrm{P} 450$ family (Figure 5A). Because there were many down-regulated genes, only the top 20 pathway types were shown (Figure 5B). These genes were mainly involved in hepatic fatty acid metabolism, PPAR $\alpha$ signaling, amino acid metabolism, glycolysis, and gluconeogenesis. The most obvious change was lipid metabolism (Figure 5B). To confirm this result, some of the mRNAs were quantitated, including Cyp4a10/14, Cpt2, Ehhadh, G6pc, Hmgcs2, Txnip, and Vnn1, revealing that they were lower, consistent with the microarray analysis (Figure 5C).

\section{Hepatocyte PPAR $\alpha$ Deficiency Promotes Hepatic Lipid} Accumulation during Liver Regeneration

PPAR $\alpha$ plays an important role in regulating fatty acid oxidation. ${ }^{43}$ Microarray analysis results indicate that hepatic $\operatorname{PPAR} \alpha$ may promote liver regeneration after $\mathrm{PHx}$ by regulating the lipid metabolism to meet the energy requirement. To study the hepatic lipid metabolism changes after PHx, oil red O staining was used to measure the hepatic lipid accumulation. Ppara ${ }^{\Delta \mathrm{Hep}}$ mice showed more hepatic lipid accumulation and increased triglyceride contents than those in Ppara $^{\mathrm{f} / \mathrm{fl}}$ mice at 12 hours after PHx (Figure 6, A and B). In accordance with this result, mRNAs encoded by genes involved in hepatic fatty acid $\beta$-oxidation, such as Cptla and Hadha/b, all decreased at 12 and 24 hours after PHx in Ppara $^{\Delta \text { Hep }}$ mice when compared with Ppara $^{\mathrm{f} / \mathrm{fl}}$ mice (Figure 6, C-E). These results indicate that hepatic PPAR $\alpha$ could promote liver regeneration by increasing fatty acid oxidation and lipid accumulation.

Hepatocyte PPAR $\alpha$ Deficiency Reduces Hepatic Glucose Metabolism Gene Expression during Liver Regeneration

Previous studies showed that PPAR $\alpha$ plays an essential role in maintaining glucose, lipid, and cholesterol homeostasis. ${ }^{44}$ Moreover, glucose metabolism is a source of energy for liver regeneration. ${ }^{11}$ Therefore, glycolysis and gluconeogenesis gene expression in liver after PHx were measured. G6pc, Pckl, $P k m$, and $P f k m$ mRNA levels were decreased in ppara $^{\Delta \text { Hep }}$ mice when compared with those in $P_{p a r a}{ }^{\mathrm{f} / \mathrm{fl}}$ mice (Figure 7, 
A-E). These results show that PPAR $\alpha$ may supply energy for liver regeneration by regulating glucose metabolism.

$\beta$-Hydroxybutyrate is a ketone body mainly produced in the liver from fatty acids during fasting, prolonged exercise, or absence of dietary carbohydrates, when the glucose supply is too low to meet the energy needs. $\beta$-Hydroxybutyrate is then distributed via the circulation to metabolically active tissues as a glucose-sparing energy source. ${ }^{45,46} \beta$-Hydroxybutyrate can promote histone hyperacetylation and reduce lipolysis and metabolic rates. ${ }^{45}$ Hepatocyte-specific disruption of PPAR $\alpha$ increased serum $\beta$-hydroxybutyrate and slightly decreased the metabolic rate at 6 and 24 hours after PHx (Figure 7F). Therefore, the energy supply was not enough for normal liver regeneration compared with Ppara $^{\mathrm{f} / \mathrm{fl}}$ mice.

\section{Discussion}

In this study, hepatocyte PPAR $\alpha$ was found to promote liver regeneration through regulating cell cycle and lipid/glucose metabolism. In addition to whole body PPAR $\alpha$ 's role in liver regeneration after $\mathrm{PHx},{ }^{26,31,47}$ the current study revealed that PPAR $\alpha$ expressed in the hepatocyte controls energy supplies to ensure normal liver cell cycle progression. A previous study showed that PPAR $\alpha$ agonist induced hepatocyte proliferation mainly dependent on hepatocyte PPAR $\alpha$ but not PPAR $\alpha$ expressed in nonparenchymal cell in the liver. ${ }^{33}$ Herein, more evidence is provided supporting a role for PPAR $\alpha$ in hepatocyte in regulating cell proliferation in the PHx model.

PPAR $\alpha$ is a ligand-activated nuclear receptor that participates in multiple pathophysiological processes, including lipid metabolism, glucose homeostasis, cell proliferation, and inflammatory response. ${ }^{27}$ PPAR $\alpha$ is mainly expressed in liver, heart, and kidney and to a lesser degree in other organs. Mice with global knockout of PPAR $\alpha$ develop transiently impaired liver regeneration after PHx, which is associated with changes in expression of cell cycle control genes, cytokine signaling, and fat metabolism. ${ }^{26}$ In the present study, conditional disruption of PPAR $\alpha$ in hepatocytes resulted in a decreased liver regeneration after PHx. Moreover, in contrast with Ppara $^{\mathrm{f} / / \mathrm{fl}}$ mice, a decrease of $C$ cnd 1 mRNA and CYCD1 protein levels was noted at 12, 24, and 32 hours in Ppara ${ }^{\Delta \text { Hep }}$ mice after PHx. CYCD1 is a key cell cycle protein that forms complexes with cyclin-dependent kinases 4 and 6 , which promote cell cycle progression from the $G_{1}$ phase to the $S$ phase. ${ }^{48}$ Consistently, Ppara ${ }^{\Delta \text { Hep }}$ mice showed decreased Pcna mRNA and PCNA protein expression at 32 hours after PHx. Furthermore, the present data indicate that the decreased CYCD1 and PCNA at the early stage of PHx in Ppara ${ }^{\Delta \mathrm{Hep}}$ mice is likely not because of activation of the STAT3/NF- $\kappa B$ pathway. These data suggest that hepatocyte PPAR $\alpha$ promotes cell proliferation by regulating CYCD1 and PCNA expression.

Transient liver steatosis is found 12 to 24 hours after PHx and is critical for normal liver regeneration, but excess hepatic steatosis and disruption of hepatic lipid accumulation before PHx impair liver regeneration in mice. ${ }^{19}$ A previous study reported that Ppara whole body knockout mice showed transiently reduced liver regeneration with decreased fatty acid $\beta$-oxidation. ${ }^{26}$ To fully understand the relationship between liver regeneration and lipid metabolism in mice, microarray analysis was performed in $P_{p a r a}{ }^{\Delta \mathrm{Hep}}$ and Ppara $^{\mathrm{f} / \mathrm{fl}}$ control mice after PHx, revealing decreased expression of mRNAs encoding hepatic fatty acid metabolism enzymes, PPAR $\alpha$ signaling, amino acid metabolism, glycolysis, and gluconeogenesis gene expression in Ppara ${ }^{\Delta \mathrm{Hep}}$ mice. In support of these findings, hepatic lipid and triglyceride contents were increased, whereas fatty acid $\beta$-oxidation gene mRNAs were decreased in Ppara $^{\Delta \text { Hep }}$ mice compared with Ppara $^{\mathrm{A} / \mathrm{fl}}$ mice at 12 hours after PHx. On the other hand, gluconeogenesis G6pc, $P c k l, P k m$, and $P f k m$ mRNA levels were decreased in Ppara $^{\Delta \text { Hep }}$ mice compared with Ppara $^{\mathrm{fl} / \mathrm{fl}}$ mice, and serum hydroxybutyrate levels increased. These results suggest that hepatic PPAR $\alpha$ promotes fatty acid $\beta$-oxidation, lipid metabolism, and glucose metabolism to meet the large energy requirement needed for liver regeneration.

In conclusion, the present study found that hepatocyte $\operatorname{PPAR} \alpha$ promotes liver regeneration after $\mathrm{PHx}$ at least partially via regulating cell cycle-related gene expression and promoting fatty acid $\beta$-oxidation and glucose metabolism.

\section{Supplemental Data}

Supplemental material for this article can be found at https://doi.org/10.1016/j.ajpath.2018.10.009.

\section{References}

1. Miyaoka Y, Miyajima A: To divide or not to divide: revisiting liver regeneration. Cell Div 2013, 8:8

2. Fausto N, Campbell JS, Riehle KJ: Liver regeneration. Hepatology 2006, 43:S45-S53

3. Michalopoulos GK, DeFrances MC: Liver regeneration. Science 1997, 276:60-66

4. Taub R: Liver regeneration: from myth to mechanism. Nat Rev Mol Cell Biol 2004, 5:836-847

5. Michalopoulos GK: Principles of liver regeneration and growth homeostasis. Compr Physiol 2013, 3:485-513

6. Michalopoulos GK: Liver regeneration after partial hepatectomy: critical analysis of mechanistic dilemmas. Am J Pathol 2010, 176:2-13

7. Michalopoulos GK: Liver regeneration. J Cell Physiol 2007, 213: 286-300

8. Michalopoulos GK: Hepatostat: liver regeneration and normal liver tissue maintenance. Hepatology 2017, 65:1384-1392

9. Wang H, Park O, Lafdil F, Shen K, Horiguchi N, Yin S, Fu XY, Kunos G, Gao B: Interplay of hepatic and myeloid signal transducer and activator of transcription 3 in facilitating liver regeneration via tempering innate immunity. Hepatology 2010, 51:1354-1362

10. Cornell RP: Gut-derived endotoxin elicits hepatotrophic factor secretion for liver regeneration. Am J Physiol 1985, 249:R551-R562

11. Huang J, Rudnick DA: Elucidating the metabolic regulation of liver regeneration. Am J Pathol 2014, 184:309-321 
12. Moreau F, Seyfritz E, Toti F, Sigrist S, Bietigier W, Pinget M, Kessler L: Early effects of liver regeneration on endocrine pancreas: in vivo change in islet morphology and in vitro assessment of systemic effects on beta-cell function and viability in the rat model of two-thirds hepatectomy. Horm Metab Res 2014, 46:921-926

13. Huang J, Schriefer AE, Cliften PF, Dietzen D, Kulkarni S, Sing S, Monga SP, Rudnick DA: Postponing the hypoglycemic response to partial hepatectomy delays mouse liver regeneration. Am J Pathol 2016, 186:587-599

14. Siu J, McCall J, Connor S: Systematic review of pathophysiological changes following hepatic resection. HPB (Oxford) 2014, 16:407-421

15. Rudnick DA, Davidson NO: Functional relationships between lipid metabolism and liver regeneration. Int J Hepatol 2012, 2012:549241

16. Yang SQ, Lin HZ, Mandal AK, Huang J, Diehl AM: Disrupted signaling and inhibited regeneration in obese mice with fatty livers: implications for nonalcoholic fatty liver disease pathophysiology. Hepatology 2001, 34:694-706

17. Yamauchi H, Uetsuka K, Okada T, Nakayama H, Doi K: Impaired liver regeneration after partial hepatectomy in $\mathrm{db} / \mathrm{db}$ mice. Exp Toxicol Pathol 2003, 54:281-286

18. DeAngelis RA, Markiewski MM, Taub R, Lambris JD: A high-fat diet impairs liver regeneration in C57BL/6 mice through overexpression of the NF-kappaB inhibitor, IkappaBalpha. Hepatology 2005, 42: $1148-1157$

19. Shteyer E, Liao Y, Muglia LJ, Hruz PW, Rudnick DA: Disruption of hepatic adipogenesis is associated with impaired liver regeneration in mice. Hepatology 2004, 40:1322-1332

20. Zhang L, Wang YD, Chen WD, Wang X, Lou G, Liu N, Lin M, Forman BM, Huang W: Promotion of liver regeneration/repair by farnesoid $\mathrm{X}$ receptor in both liver and intestine in mice. Hepatology 2012, 56:2336-2343

21. Borude P, Edwards G, Walesky C, Li F, Ma X, Kong B, Guo GL, Apte U: Hepatocyte-specific deletion of farnesoid X receptor delays but does not inhibit liver regeneration after partial hepatectomy in mice. Hepatology 2012, 56:2344-2352

22. Fernandez MA, Albor C, Ingelmo-Torres M, Nixon SJ, Ferguson C, Kurzchalia T, Tebar F, Enrich C, Parton RG, Pol A: Caveolin-1 is essential for liver regeneration. Science 2006, 313:1628-1632

23. Ren G, Wang ZC, Cui YY: [Role of caveolin-1 in hepatocyte proliferation and liver regeneration] Chinese. Sheng Li Ke Xue Jin Zhan 2009, 40:341-344

24. Liu HX, Fang Y, Hu Y, Gonzalez FJ, Fang J, Wan YJ: PPARbeta regulates liver regeneration by modulating Akt and E2f signaling. PLoS One 2013, 8:e65644

25. Gazit V, Huang J, Weymann A, Rudnick DA: Analysis of the role of hepatic PPARgamma expression during mouse liver regeneration. Hepatology 2012, 56:1489-1498

26. Anderson SP, Yoon L, Richard EB, Dunn CS, Cattley RC, Corton JC: Delayed liver regeneration in peroxisome proliferator-activated receptor-alpha-null mice. Hepatology 2002, 36:544-554

27. Lefebvre P, Chinetti G, Fruchart JC, Staels B: Sorting out the roles of PPAR alpha in energy metabolism and vascular homeostasis. J Clin Invest 2006, 116:571-580

28. Corton JC, Anderson SP, Stauber A: Central role of peroxisome proliferator-activated receptors in the actions of peroxisome proliferators. Annu Rev Pharmacol Toxicol 2000, 40:491-518

29. Peters JM, Cattley RC, Gonzalez FJ: Role of PPAR alpha in the mechanism of action of the nongenotoxic carcinogen and peroxisome proliferator Wy-14,643. Carcinogenesis 1997, 18:2029-2033

30. Tien ES, Gray JP, Peters JM, Vanden Heuvel JP: Comprehensive gene expression analysis of peroxisome proliferator-treated immortalized hepatocytes: identification of peroxisome proliferator-activated receptor alpha-dependent growth regulatory genes. Cancer Res 2003, 63:5767-5780

31. Wheeler MD, Smutney OM, Check JF, Rusyn I, Schulte-Hermann R, Thurman RG: Impaired Ras membrane association and activation in PPARalpha knockout mice after partial hepatectomy. Am J Physiol Gastrointest Liver Physiol 2003, 284:G302-G312

32. Yuan X, Yan S, Zhao J, Shi D, Yuan B, Dai W, Jiao B, Zhang W, Miao M: Lipid metabolism and peroxisome proliferator-activated receptor signaling pathways participate in late-phase liver regeneration. J Proteome Res 2011, 10:1179-1190

33. Brocker CN, Yue J, Kim D, Qu A, Bonzo JA, Gonzalez FJ: Hepatocyte-specific PPARA expression exclusively promotes agonist-induced cell proliferation without influence from nonparenchymal cells. Am J Physiol Gastrointest Liver Physiol 2017, 312:G283-G299

34. El-Jamal N, Dubuquoy L, Auwerx J, Bertin B, Desreumaux P: In vivo imaging reveals selective PPAR activity in the skin of peroxisome proliferator-activated receptor responsive element-luciferase reporter mice. Exp Dermatol 2013, 22:137-140

35. Wang H, Feng D, Park O, Yin S, Gao B: Invariant NKT cell activation induces neutrophil accumulation and hepatitis: opposite regulation by IL-4 and IFN-gamma. Hepatology 2013, 58:1474-1485

36. Mitchell C, Willenbring $\mathrm{H}$ : A reproducible and well-tolerated method for 2/3 partial hepatectomy in mice. Nat Protoc 2008, 3: $1167-1170$

37. Mitchell C, Willenbring H: Addendum: a reproducible and well-tolerated method for 2/3 partial hepatectomy in mice. Nat Protoc 2014, 9:1532

38. Qu A, Taylor M, Xue X, Matsubara T, Metzger D, Chambon P, Gonzalez FJ, Shah YM: Hypoxia-inducible transcription factor 2alpha promotes steatohepatitis through augmenting lipid accumulation, inflammation, and fibrosis. Hepatology 2011, 54:472-483

39. Yang Q, Ito S, Gonzalez FJ: Hepatocyte-restricted constitutive activation of PPAR alpha induces hepatoproliferation but not hepatocarcinogenesis. Carcinogenesis 2007, 28:1171-1177

40. Peters JM, Aoyama T, Cattley RC, Nobumitsu U, Hashimoto T, Gonzalez FJ: Role of peroxisome proliferator-activated receptor alpha in altered cell cycle regulation in mouse liver. Carcinogenesis 1998, 19:1989-1994

41. Tachibana S, Zhang X, Ito K, Ota Y, Cameron AM, Williams GM, Sun Z: Interleukin-6 is required for cell cycle arrest and activation of DNA repair enzymes after partial hepatectomy in mice. Cell Biosci 2014, 4:6

42. Qu A, Shah YM, Matsubara T, Yang Q, Gonzalez FJ: PPARalpha-dependent activation of cell cycle control and DNA repair genes in hepatic nonparenchymal cells. Toxicol Sci 2010, 118: 404-410

43. Ferre P: The biology of peroxisome proliferator-activated receptors: relationship with lipid metabolism and insulin sensitivity. Diabetes 2004, 53(Suppl 1):S43-S50

44. Chakravarthy MV, Pan Z, Zhu Y, Tordjman K, Schneider JG, Coleman T, Turk J, Semenkovich CF: "New" hepatic fat activates PPARalpha to maintain glucose, lipid, and cholesterol homeostasis. Cell Metab 2005, 1:309-322

45. Newman JC, Verdin E: Ketone bodies as signaling metabolites. Trends Endocrinol Metab 2014, 25:42-52

46. Newman JC: Verdin E: beta-hydroxybutyrate: a signaling metabolite. Annu Rev Nutr 2017, 37:51-76

47. Rao MS, Peters JM, Gonzalez FJ, Reddy JK: Hepatic regeneration in peroxisome proliferator-activated receptor alpha-null mice after partial hepatectomy. Hepatol Res 2002, 22:52-57

48. Kamarajugadda S, Becker JR, Hanse EA, Mashek DG, Mashek MT, Hendrickson AM, Mullany LK, Albrecht JH: Cyclin D1 represses peroxisome proliferator-activated receptor alpha and inhibits fatty acid oxidation. Oncotarget 2016, 7:47674-47686 